\title{
"Diálogos Máximos"
}

POr ABRAHAM VALDELOMAR

EN EL HIPODROMO

Aristipo.-

Es buen carro este de gringote. Raudo como un albatros, negro cual cuervo de Poe, brillante como una piedra preciosa, ágil como un dardo de cupido.

Manlio.-

-Quisiera entender léqué dice la sirena...

Aristipo.-

-Reparásteis en tosligangrejostque se os ha servido en el almuerzo. Los marinososenuenegenerad, buenos "gourmets". Bonita casa. El Paseo Colón esté terroso. Llegaremos a la cuarta carrera. Grato ha de ser un accidente en este carro de gringote. Es como morir en un trono. Convendría que gringote le pusiera un nombre "chic" a este carro, que tiene ya el prestigio de habernos llevado...

Manlio. -

-Aristipo, sacad la tarjeta que os dió el señor Rodríguez Mariátegui, eso os evita pagar dos soles...

Aristipo.-

- Gentil persona es el señor Rodríguez Mariátegui. Este tiene un gesto de displicencia dispéptica...

Manlio. -

Aristipo.-

-Bella explanada. Rosales, mujeres, juventud, discreta elegancia, aire, luz, guantes, pieles, amigos, caballos... Esto es grato. El paisaje es alegre en verdad. Paisaje inglés.

Manlio. -

-Observad... 
Aristipo.-

- ¿Qué suerte de mono policromo va encaramado scbre aquel gentil caballo?

Manlio. -

- No es un.mono. Calaos los lentes. Es un jocriey.

Aristipo.-

- ¿Qué es un jockey?

Manlio. -

-Generalmente un sujeto que aprovecha su mezquindad fisiológica para cabalgar un caballo y que se empeña en conseguir que el caballo sea cómplice de sus propósitos casi siempre dudosos...

Además a estos microbios se les pesa como el arroz, el garbanzo, la manteca...

Aristipo.-

- ¿Ganaré?

Manlio.-

-Eso es cuestión del destino. No hay libre albedrío. Dependen los hombres del signo zodiacal, de la estrella favorita de las fuerzas ocultas del Gran Todo...

Aristipo.-

-Y en el Perú, hasta del Gobierno. Sí, pero el destino se presenta a los hombres polliforme como Satanás. En los bellos tiempos de la Latinidad, el Destino hablaba desde el corazón de la montaña por losilabiofa dotaterantes de una virgen púdica y electa; en nuestros gín es mas vario. A veces, sobre el tapete verde, el Destino se encarna en el cuerpo caduco de un macaco tuberculoso y viejo; otras veces en la anciana haraposa y desdentada, india y panzona, que ofrece un huachito de a mil; otras en la raposa criatura, bella y sin particla de bautizo, famélica y ojerosa, que junto con el billete de a mil os ofrece lo que le pidáis; y otras veces, el Destino que se envilece, viene a ti, Manlio, en forma de billete de tranvía por las manos de un hombre peludo y con gorrita, que a cambio de cinco céntimos hace nacer espectativas de lucro en el alma pueril del ingenuo que espera sacarse veinte libras con tan poco desarrollo de energías; pero a veces, y este es nuestro caso, el Destino se presenta encarnado en un caballo arrogante y nervioso, en el Hipódromo.

Manlio.-

-Pero Virgen, Macaco, Vieja o Moza, Conductor o Caballo, el Destino es el mismo, Arístipo. Esquivo y versátil, inconst ciente y sorpresivo, cruel y generoso, que huye de quien le busca y sorprende a quien le desdeña... 
Aristipo.-

- Sí. Más hay grados. Delante de un chino flaco tentar al Destino carece de encantos. Sobre el tapete verde parece envilecido y ruín todo contrato con ese valor intangible.

-Aquel mestizaje de almas, desmontellante y grotesco. La suerte de la Beneficencia, ese papelillo verde y signado, no me place, porque él, pegado al cuadro de un San José de litografía, es la esperanza de quienes ya nada esperan. El billete del tranvía quizás sería más apreciable si en vez de ser desglosado por dedos nudosos y velludos, con uñas negras y convexas, lo fuera por manos pulidas y educadas en la noble escuela de una manicure prolija y ostensible. En cambio, echaré todo mi dinero a la probabilidad de las cuatro ágiles patas de un caballo de fina raza y conocida prosapia. Hay que sostener una verdad elemental: los caballos de carreras son la aristocracia de la especie. "Fugace" es a los suyos lo que Jorge Brumell a la sociedad inglesa, Tu no concibes, Manlio, a Febo halando de un coche hermanado a un caballo raposo, flaco, desconocido y anónimo. Cuahdo uno que fue noble y veloz caballo envejece o se debilita, no se le manda a tirar de una carreta, como a un noble yiejo que se le destina con cuarenta soles en un Ministerio, nô. Af caballo se le destina á la noble tarea de perpetuar su espeeiel..

-Porque los caballos más afortunados que los hombres, inútiles para toda otraolaborenaum song, viriles...

-Una voz.-

_ i57 Kilos es demasiado!

Otra voz.-

- i 7 boletos al ganador!

Otra voz.-

-Me dijo que sí, pero tú comprendes...

Otra voz.-

- Sí, hija mía, pero verde con colorado...

Manlio.-

-Qué ojos azules, Aristipo. Esas pupilas parecen aquellas bolas de a centavito que comprábamos de chiquillos: azules, transparentes, nuevas, inexpresivas, frías y bellas...

Aristipo.maturas.

-Y las pestañas negras parecen copiarse en las orejas pre-

Esos ojos ocúrrenseme no reflejar más que el temor. Tal como una gacela asustada.

Una voz.-

—iMaldita sea! Pierdo treinta soles. 
Aristipo.-

- Hay gentes que se exaltan cuando pierden.

Manlio.-

- Perder es distinguido y correcto. Poca gente conoce la función deliciosa y la aristocrática elegancia de perder. Molestarse porque se pierde es como inmutarse cuanclo se cae y rompe el monóculo.

Aristipo.-

- ¿Es hora de apostar?

Manlio.-

-Sí. Apostemos. ¿Hola, como va?...

Aristipo.-

$-i$ A quién saludais?

Manlio.-

-Esto no es un saludo. Es una simple constatación... ¿A qué caballo apostamos?

Aristipo.-

-Todo proceso volitivo requiere lógica. Hay lógica para todo. Hasta para lo ilógico. Todo obedece a una ley preestablecida. Hay un ritmo universal, Manlio. En estos procesos triunfan las minorias. ¿Cuál es el favorito? “Febo"? Pues bien, es seguro que perderé "Febo". ¿ ¿uántos valores intervienen, Manlio, en el éxito de una carrera?"

Veamos. Un señor que dispone de dinero compra un stud, adquiere caballos, contrata qockeys, hate sus inscripciones, tiene un preparador; bien, este es uno de los valores, es lo que podemos llamar el valor-propietario. Un mono de lamentable y pobrísima catadura es el jockey. A este le interesa que el caballo que cabalga gane o no gane; él puede sofrenarlo, excitarlo, y hasta matarlo, bien, éste es el valor que podemos llamar el valor jockey.

Hay un caballo que no se da cuenta de las intrigas que a su lado se desarrollan y que procede a su libre albedrío; este animal depende de una serie de circunstancias: el pasto, el training, la preparación, el humor, el clima, la pista y hasta la manera de cabalgarlo; a este podemos llamar el valor caballo; hay aún las distancias, las partidas, etc., total veinte valores que intervienen en cada carrera. En una carrera de cinco ca-

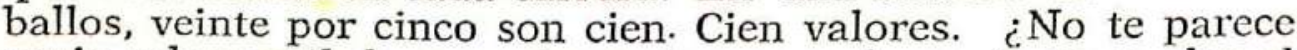
necio saber cuál de esos cien valores es el que te va a dar el triunfo? Más probabilidades hay en jugar al sello y cara. Resúmen: se debe apostar al azar... O ir en contra de la erudita mayoría...

Una voz.-

El starter! 
Aristipo.-

- ¿Qué es starter?

Manlio.-

- Starter significa Juez de partida. Es el hombre que tiene sobre sí la pesada tarea de poner de acuerdo a varios caballos. En este pueblo de libertos, Aristipo, es difícil poner de acuerdo a dos hombres. iImaginad lo que es poner de acuerdo a cinco caballos.

Aristipo.-

- iAquel caballero de la desviada pupila?

Manlio.-

-El handicaper.

Aristipo.-

- ¿Es condición que desvíe la pupila?

Manlio.-

-Basta con que sea un gentleman. Y lo es.

Aristipo.-

-Lo cual me place.-

Voces.-
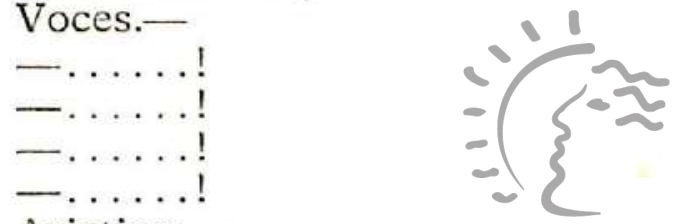

Aristipo.-

- ¿Por qué chillan Biblioteca de Letras

Manlio.-

-Una mala partida.

Aristipo.-

-Los caballos ¿no se han puesto de acuerdo?

Manlio.-

—No, un bribón de jockey...

Aristipo.-

${ }_{-}$¿Los hay bribones?

Manlio.-

-En grado máximo.

Aristipo.-

-Pero ¿qué quieren esas gentes airadas y agresivas?

Manlio.-

- Comerse crudo al starter.

Aristipo.-

- Lo cual revela mal gusto. Pero ese caballero es mi amigo. Además yo he ganado con "Ocasión". Debo acompañarle. Y voy...

Manlio.- 
-Aristipo! Aristipo!! Aristiiiiiipo!

¿Dónde os metéis bellaco? Os patearán...

\section{(Tumulto).}

\section{$-\dot{Y} \mathrm{Y}$ ?}

Aristipo.-

-Una pierna animal de bellaco me ha tizado una patada. Pero no se han alterado los pliegues de mi corbata. ¡Cuán bello es sentirse odiado por una multitud exaltada! Bien cierto es que pegan, pero en cambio sudan. Una por otra.

Manlio.-

- ¿Qué os pasa, Aristipo?

Aristipo.-

Manlio.-

—¿Qué tenéis? ¿Qué dolor os invade? ¿Sufrís? ¡Hablad!... Aristipo.-

Manlio.-

-Mas, por Dios, explicaos! ¿Qué tenéis?...

Aristipo.-

- ¡Oh, estos inviernos- $\$$ in $c$ crepúsculos!...

(De LA PRENSA, 22 de junio de 1916).

"Jorge Puccinelli Converso"

\section{II}

\section{EN EL PALAIS CONCERT}

\section{Manlio.-}

- He aquí, Aristipo, que ante este "ice cream soda", sanguinolento y espumoso, del Palais Concert, Wagner, sonando en las vienesas cuerdas, tiene un sabor de pastel. Se diría un Wagner con crema...

Aristipo.-

-Un Wagner con crema supondría una idealización de la crema. Mas piensa, Manlio, que si seguimos el consejo del divino Platón, de llegar a la ley por generalizaciones sucesivas, la música de Beethoven sería una música de compota; Bach tendría sabor de limonada, por su caprichoso contraste acidulado y nuestros músicos serían "de agua de canela". El huaynito 
tiene, en conclusión, espíritu de chicha de jora y la marinera sabor a frijoles con papada...

Manlio.-

- ¿Has dicho que la música es una idealización? Pues bien. El ideal debe ser voluble como el viento, como la nube, como la vida. El ideal no siempre es una cosa incorruptible e incorpórea. Hay hombres cuyo ideal sería el nirvana y otros cuyo ideal se limita a un churrasco con papas fritas. Grata cosa es acercarse al ideal. ¿Tienes tú un ideal, Aristipo?

Aristipo.-

- Mi ideal personal sería ser empleado de una joyería. Mi ideal social es que un amigo íntimo mío se case con una coja... Manlio.-

$-i$ No tienes un ideal religioso?

Aristipo.-

- Mi ideal religioso habría sido nacer en tiempos de Cristo y pasar como él una noche de luna en Tiberiades.

Manlio.-

- Necia y absurda oposición de siglos...

Aristipo.-

- ¿Crees, Manlio, que una botella de soda puede llevarnos a la comprensión del absōlutoo trascendente?

Manlio.-

-Es como si me preguntaras si de la oreja que le dieron a "Limeño", el domingid,liseepudięrarpasar a comprender el ín-

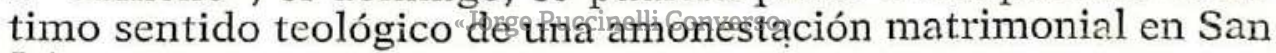
Lázaro.

Aristipio.-

- Heme aquí, Manlio, en la esquina de "Divorciadas", esperando el carro de conexión. Un sol insolente y procaz cual carretero, cae con violencias de subprefecto. Pienso entonces en un refresco; una botella de soda. Pero al entrar a la taberna mis ojos ven un ataúd, dos ataúdes, tres ataúdes. Un hombre pálido, trasnochado y borracho de un sincero dolor, discute el precio de una caja con otro sujeto, el dueño, raro tipo que me sorprende. Estos hombres que negocian con el "confort" de los muertos adquieren un aspecto de ultratumba. El provedor de cajas de muertos es gordo, pero su gordura se derrite en una grasa opaca, tal como la que tienen los lívidos rostros de los cadáveres de hombres casados a los cuarenticinco años. Todo en él parece sacado de diversos nichos. Da la sensación de un hombre vestido por el cadáver de un sastre, peinado por un peluquero muerto, calzado por el esqueleto de un zapatero y alimentado por un "maitre d' hotel" que saliera de su nicho con la servilleta al brazo y las cuencas vacías... 
Yo tuve miedo, Manlio; pero entré. Convencionales Cristos de plaqué en los anaqueles. Cristo en plaqué me daba la sensación de un cristo de servicio de mesa. La cruz de plaqué no me evocaba el Calvario sino la sopera. Donde decía INRI yo creía entender: MENU. Unos ángeles con alas de papel de cometa, vigilaban simétricamente. ¿Te imaginas, Manlio, dos ángeles con alas de papel de cometa? Parecían dos "pavas cantoras" celestiales que estuvieran al servicio de un Dios "Pandorgo". Un cachaco se detiene a la puerta y se recuesta sobre uno de los dichos ángeles. Entonces pienso que nuestros ángeles debían usar poncho y sombrero de jipijapa: un ángel con vara de la ley que estuviera al servicio de un hombre obeso vendedor de ataúdes. Ahora el comprador discute cuánto le cobrarán por inscribir el nombre de su deudo en la placa del cajón...

Manlio.-

- ¿Quién era el muerto?

Aristipo.-

-Un empleado de comercio. El clucño de los ataúdes despertaba el apetito de su cliente, mostrándole los dibujos de las clases de entierros.

$\mathrm{Si}$ iba su deudo en primnera clase, pasaría por el Jirón de la Unión, halado por seis mulas con negra mantilla española. Un par de negros viejos, rétintos, sombríos - símbolo de lo misterioso- irían de annigasec La cañza sería cubierta de alegorias doradas a purpuoinapucillevaríaspor coronación un santo de madera.

¿Te parece plácido, Manlio, que cuando uno se muera le lleven a la última morada, seis burros con mantilla española?

Manlio.-

- Seis burros con mantilla española son una complicación social, el rito. De esta suerte, cuando el entierro es de tercera clase ¿qué linaje de animales halarán al muerto?

Aristipo.-

-Fácil es saberlo con la leal ayuda de la lógica. Si para un muerto de primera son seis burros, para uno de segunda se rán cinco carneros y para una de tercera cuatro gatos...

Manlio.-

- ¿Y el día en que el muerto sea burro?

Aristipo.-

-Repara, Manlio, que los burros mueren sin protocolo. Además no testan...

Manlio.-

- Salgamos de aquí, Aristipo. Salgamos en pos de nuestros nuevos amigos Mercadante y Heliodemo. Mercadante tiene 
en su aparador vino de uva de las cepas ubérrimas de Ica. Heliodemo, en sus anaqueles, libros selectos guarda. Y no abuses tú de los pasteles porque al salir pudieras caerte en una de estas gentiles figulinas, que aunque no son abejas son melosas y plácidas. Nuestras mujeres son como pasteles de fresa: gratas, bellas y de buena pasta, pero a veces las fresas...

Aristipo.-

Paga y da al criado la soldada que aquí apodan propina. En estos países democráticos una genuflexión de ciudadano vale un real en cobre...

(De LA PRENSA, 15 de febrero de1917).

\section{III}

Manlio.dinarias... .

-Durante el sueño, dice Plotino, nacen las ideas extraor-

Aristipo.-

-Lo extraordinario, Manlio, es inconexo, porque es una sucesión de ideas culminantes Lo extraordinario es como un conjunto de cumbres, entre 1 as cuales hay vacíos; y tales vacíos producen la inconexión, la linea quebrada, el contraste. Sin contraste no cabe grandeza. El contraste asesina a la monotonía, de igual manera que ef agudo puñal de un coolí destripa a un cerdo cebado. . .

Manlio.-

- Te apresuras a contestar sin tener la idea íntegra extendida sobre la mesa de operaciones. Así procedería un médico que quisiera autopsiar a un hombre vivo. Te digo que en el sueño nacen las ideas extraordinarias pero sin el control de la conciencia. Los hombres se dejan deslumbrar por el fulgor de una idea brillante habida en el sueño, la traducen fielmente, y fracasan. El método consistiría en aplicar mi ley reguladora y eficaz; las ideas extraordinarias del sueño, expuestas bajo el control eficaz de la vigilia. . .

Aristipo.-

-Yo he tenido un sueño, quiero que tú lo controles. Soñaba yo con una dama obesa con chaleco, con un chambelán de un gran rey y con un plato de tallarines. El copero mayor servía un exquisito vino...

Manlio.-

-Bien. Los sueños están en relación con la capacidad cerebral de quien los tiene. El pastor soñará con que le roban una cabra. La dama con que le obsequian un sombrero. El es- 
critor bellaco con que le aplauden los estultos y tú con una dama obesa con chaleco. Y no es el sueño cuestión de profesiones liberales, no. El frayle sueña siempre con el demonio, pero cuando sueña con Dios, Dios se le aparece con barbas y una clámide a manera de camisa de dormir, con un triángulo y una paloma mal dibujada en la cabeza. El frayle torpe no concibe sino a un Dios que se parezca al padre Prior. En cambio el filósofo sueña con un Dios impalpable, oculto y presente, difuminado en el paisaje, en el espíritu y en las fuerzas inexplicables.

Aristipo.-

-Luego mi sueño $\dot{e}$ es sueño de sandio?...

Manlio.-

-No será tal si sabes aprovecharlo. Tú has soñado con una dama barrigona que tenía chaleco, con un chambelán de una gran rey, con un plato de tallarines y con un copero y una copa de vino...

Aristipo.-

-Así es verdad.

Manlio.-

Piensa y busca en todō esto lo- que se debe pensar y buscar en todo lo objetivo que cae bajo el poder de los sentidos: el más y el menos, el positivo y el negativo, la materia y la fuerza, el cuerpo y la idegliale dięn Lyteds mal, el objeto y la sensación, en suma: el almaoyelascicosasiverson

Para ello es menester un espíritu avizor y sutil. Un gran rey, un chambelán y un copero te pueden dar, si sacas del plato de tallarines la esencia, el substractum, una sensación de lo heroico... ¿En qué cosa reside el alma de los tallarines?

Aristipo.-

-En los fideos.

Manlio.-

- Necio! piensa y medita. Los fideos son el cuerpo, más no el alma de los tallarines... .

Aristipo.hongos?

-El alma de los tallarines ¿reside acaso, Manlio, en los Manlio.-

-Bestia encanallada y oxidado cerebro, el alma de los tallarines reside en lo más intenso de los tales. Un hongo ¿te da sensación definida de tallarines?

Aristipo.-

-No.

Manlio.-

-Una rama de laurel ¿de qué habla a tu espíritu? 
Aristipo.-

-De la Victoria Inmortal.

Manlio.-

-Bien. Tras la Victoria está ¿qué otra idea en el laurel? Aristipo.-

-Eres estupendo y desconcertante: ¡los tallarines!

Manlio.-

- Pasa estas ideas por el fino cedazo de la lógica y dime ¿qué queda en el cedazo?

Aristipo.-

-Que el alma de los tallarines es el laurel.

Manlio.-

- Claro. El laurel en los tallarines evoca la victoria. El laurel en el combate evoca los tallarines. Tienes, pues, que tu sueño de los tallarines te lleva al más alto sentido de la victoria inmortal; y en cuanto a la dama del chaleco ¿qué te dice el chaleco?...

Aristipo.-

-Nada.

Manlio.-

- Buen lerdo sois, señoy Mentecato. El chaleco es el alma de tu sueño y te sugerirá ideas de sociología comparada, así como el copero y el vino añejo pudieron hacerte pensar en la idea pura.

El chaleco, esta prenda superflua, anodina y sin carácter, es el espiritu de los simulitabres y mediocres. Así como el calzoncillo con tiritas es la encarnacion biológica del coronel del 95, así también, el chaleco es el símbolo del falso merecimiento, del arribismo sin derecho, de la presunción infundada.

El chaleco quiere tener las mismas prerrogativas del saco, pero carece de mangas. El saco engalana al sujeto, mas el chaleco lo deprime. Y siendo él el que da el verdadero aspecto grotesco al personaje, a la hora de la clasificación todos dicen: "Un hombre grosero, sin saco"; o "Un mal-criado en mangas de camisa". Nadie apunta: "Un hombre en chaleco". Farsante y ostentoso quiere exhibirse siempre, y sólo exhibe, naturalmente, lo único que, siendo su mejor parte, sólo sirve para cubrir el repugnante abdómen de los hombres. A la manera de esos que no llevan camisa y usan chaqué, él no tiene mangas, y el resto de su cuerpo es de forros baratos, pero siempre es él quien primero se luce., Todo lo que posee lo lleva encima y lo manifiesta con impudor: la cadena, el dije, la brújula, la palomita de plata, el guarda pelo... En suma, el chaleco tiene el alma de joven pobre, sicología de amanuense archivero, porvenir de guardamarina. .

(De LA PRENSA, 5 de marzo de 1917). 
CON ALEJANDRO SMALLENS

Alejandro Smallens, director de la orquesta de Anna Pavlowa.-Un hombre de talento exquisito, Máxi. mo Gorki y Kropotkine, sus amigos.- Baudelaire, Verlaine, Mallar. mé y las estampillas.

\section{II}

$\rightarrow$

-Después, la conversación đestizó las cuentas de su rosario de esta manera:

- ¿Y conoce usted a Máximo Gorki?

- Sí, señor. Siendeibłuseca sqy ung admirador fanático del compatriota ilustre. Admirecale Esouess todo: su literatura, su rebeldía, su espíritu indescriptible, su vida, todo, todo, porque Gorki es un ser extraordinario, fantástico...

-Le conoció Ud. personalmente, Alex?

-Sí, por mi fortunna. Yo gozo recordando al "insigne". Gozo de que aquí en el Perú, un escritor tenga la gentil idea de preguntarme por Gorki. Porque no se puede pensar en mi Patria sin evocar la figura del creador de tantas bellezas, de aquel artista libre y sincero, errabundo y abnegado, desprendido y soberbio. Me pregunta usted por Gorki y yo quiero decirle muchas cosas de mi amigo ilustre y célebre... Siento solamente no expresarme bien en español.

-Expresaos, señor amigo, en francés...

- ¿Le comprendéis?

-Le amo y poseo, señor.

-Porque si no podría hablaros en italiano si el italiano...

-Le poseo y amo igualmente.

-Bien. He aquí una anécdota de Gorki. Hace pocos años Máximo Gorki anunció su visita a los Estados Unidos en misión de propaganda revolucionaria. El barco amaneció una mañana en Nueva York. Fueron a encontrar a la nave en una 
pequeña embarcación, para dar la bienvenida al novelista, Mark Twain y los más ilustres escritores americanos. Gorki se alojó en un hotel de la Quinta Avenida. Le diré a usted lo que es la Quinta Avenida...

- La conozco, Alex, siga usted su relato...

-Bueno. Lo más notable de Nueva York desfiló por los salones del hotel. Grandes damas, millonarios, banqueros, escritores, artistas. Los rusos residentes en la ciudad pedimos a Gorki la primera conferencia en el más grande lugar que encontramos para tal fin. Todo iba maravillosamente. Salió el "insigne". Jamás tuvo artista alguno más numerosos espectadores ni tan vehementes ovaciones. Se le llevó en hombros al escenario, las damas besaban su ropa, los caballeros se descubrían, llorando a su paso. El gran escritor salió al escenario y... enmudeció. No pudo, emocionado tan intensamente, decir una palabra, ipero lloró!

-Y usted está a punto de hacerlo...

-Discúlpeme, Máximo Gorki es el alma de Rusia, es el grito nacional, es el espíritu de la estepa y del frío, del dolor hondo y del grito rebelde. De una fealdad mitológica, usted se acerca a él, luego le oye hablar luegófl le mira con su mirada extraña, dulce y apostólica, luego él-sonríe y usted cae de rodillas. Sí, ¡de rodillas!

- ¿Es afortunado Gorki?

- No es rico peroinhumeale fialtątodo lo necesario. Tiene un amigo íntimo, un Hermhecrio, lilipnverdadero hermano, el más grande de los cantantes del mundo: el bajo Chaliapine. Cuando eran ambos jóvenes, cuando en Rusia en una pequeña aldea se morían de hambre los bohemios, Chaliapine propuso a Gorki ofrecerse a un empresario de ópera barata como cantantes. Entonces ni Gorki era literato ni Chaliapine sabía para qué había sido creado. El empresario los recibió - me lo ha contado el propio Máximo-y les hizo cantar. Cantó Gorki, luego cantó su compañero. El empresario dijo a Gorki:

-Usted me conviene. Tiene Ud. voz; pero Ud. Chaliapine dedíquese a barrer el hielo en la Perspectiva Newski...

-Y Gorki cantó?

Sí, y aquella noche Chaliapine que es hoy primer bajo del mundo, cenó gracias a las "facultades de cantante que tenía Máximo Gorki..."

- ¿Conoce Ud. a algún otro ruso ilustre?

Sí: a Kropotkine. Es un apóstol...

-Hábleme Ud., Alejandro Smallens, cosas que me interesen. ¿Os gusta la poesía?

-Tengo dos grandes pasiones... 
-La música y...

$\rightarrow$ No. La Filatelia y...

- iEs usted coleccionista de estampillas?

-Sí, señor. ¡Qué quiere! No depende de mí. Es una puerilidad que me seduce.

- ¿ Filatélico y qué, señor filatelista?

-Y admirador de los poetas decadentes; de ciertos poetas. Quiero a Baudelaire tanto como a un raro sello de la India; Verlaine me gusta cual si fuera una estampilla de 1813; Mallarmé; Rodembach...

- ¿Os gusta la música de Wagner?

-Mucho, mucho, muchísimo... ¡Oh, Tristán e Isolda!

- ¿Cuál es en su concepto la mejor ópera del mundo? - ¡Carmen! Es la ópera perfecta; la maravilla. Así lo ha dicho también Strauss...

- ¿Conoce Ud. a Nicoletti-Korman el bajo de ópera?

-Mucho, ¿y usted? mi amigo...

-Estuvo en Lima, es una celebridad; fue, naturalmente.

-Ahora trabaja en el Liceo de Barcelona.. .

-Sf. Ayer recibí una carta suya con el programa de la temporada.. Usted, ¿de qué parte de Rusia es?

-De San Petersburgo: Me eduqué en Estados Unidos y en Francia... Soy el único que ha dirigido la gran banda de Susa, el famoso director americano Fue, justamente, para que danzara Anna Pavlowa. Ese es uno de mis mejores e inolvidables triunfos... ¡Cuidado! le ha caído la ceniza del cigarrillo...

\section{III}

\section{IV}

Después de la conversación deslizó las cuentas de su rosario interminablemente. .

\section{V}

Dieron las seis.

(De LA PRENSA, 24 de mayo de 1917) 


\section{$\mathrm{V}$ \\ UNA CONVERSACION CON EL DIABLO}

(Entrevista con el ilustre actor italiano Luigui Nicoletti Korman. El insigne actor, es amigo de D'Annunzio. Cosas interesantes).

-Buona notte, signor Diabolo!. .

-Buona natte, carissimo...

Era el diablo, el propio y mismísimo cornudo de las patas de chivo, el rebelde peregrino, el singular ingenio que dio al traste con la pobre Margarita; el protéico personaje que ha dado tanto que hacer a los hombres desde la Biblia hasta nuestros días; el que quiso sorprender a Jesús en la cima del monte; el que llevó a Europa las pestes de la Edad Media; el que trajo a Pizarro al Perú; el ilustre entrometido que armó la guerra europea; el que cargó las carabinas el cuatro de febrero; ese era el mismo que nos recibía, con su gran manto constelado, decorado de sapos, lagartos, buhos y culebrones, bicorne, con las cejas levantadas y divergentes, con la risa característica, en un camarín del teatro Municipal

Aquella noche daban_Mefistófeles.

No era el señor Nicoletti encarnado en el Demonıo, era el mismísimo Demonio encarnado en el ilustre actor lírico, señor Nicoletti.

-Si acomodi. Biblioteca de Letras

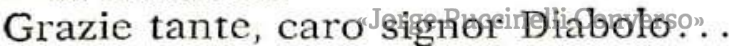

El señor Nicoletti acababa de dejar su trono en los infiernos, caído el telón después del tercer acto de la obra, y su ayuda de cámara, un joven de vivos ojos que también debe ser un demonio, le ayudaba a desvestirse.

-Sois un gran actor, Diablo. Vuestro nombre había llegado hasta nosotros desde hace mucho tiempo.

Sabemos que habéis trabajado con los más ilustres personajes de la escena universal. Sabemos que sois uno de los bajos más célebres del mundo. Sabemos que conocéis y tenéis amistad con el Príncipe D'Annunzio; sabemos que a una gran cultura musical unís una gran cultura literaria; sabemos que habéis trabajado en los mejores teatros del orbe; en Milán, en París, en Londres, en San Peterburgo, en Viena, en Madrid y en Barcelona. Quiere Ud. darnos un reportaje...

-Ya me parece inútil porque vos, señor, lo habéis dicho todo...

-EI Diablo se rasca un cuerno, hace un gesto, sonrie, y continúa. ma...

- Le diré algo. Yo comencé mi carrera en la Banca di Ro- 
- ¿En la Banca?...

- Sí. Yo era empleado en la Banca. Un día me ofrecieron dos puestos. Uno para pasar, mejorando, a la Banca de Italia, y otro para cantar en un teatro cerca de Roma. Yo, mientras trabajaba en la Banca, estudiaba en el tiempo que tenía libre, la música. Mis economías me servian para dedicarlas a pagar un profesor... Acepté la propuesta. .

-De la Banca...

-No; del teatro. .

- ¿Después?...

Después seguí... hasta ahora.

No he vuelto a salir del teatro...

- ¿Qué opina usted de Wagner?..

-Oh Wagner. Me seduce. Adoro la música italiana, pero quisiera cantar siempre la música wagneriana...

$-i$ Ha hecho usted el teatro de Wagner?...

He hecho la tetralogía: El oro del Rhin, las Walkirias, el Crepúsculo de los Dioses y Sigfrido en el teatro imperial de Budapest, con una compañía de alemanes donde yo era el único italiano, aquella compañía acababa de hacer la temporada oficial de Beiruth...

- Cuénteme, señor caballero, algunas cosas íntimas... periodista.

Sois de una encantadora indiscreción... Sois un buen

Nosotros somos cuibliotefa de Letras

Yo soy romano. Tengo un bravo sobrino en la línea de fuego, ha sido herido; tiene 20 años. Es oficial.

De mis tres hermanos uno es secretario de la Banca de Italia; otro es abogado $\mathrm{y}$, actualmente, un convalesciente de las grandes heridas que recibió en esta guerra funesta y el otro es también actor, es un barítono de una larga y meritísima carrera artística. Yo mismo poco después de debutar, fui a hacer mi servicio durante tres años de soldado. Conozco a Sem Benelli y yo fui uno de los primeros ejecutores de su famosa ópera A. more dei Tre Ré. En mis últimos tiempos he merecido el honor señaladísimo de haber sido presentado en Turín a S.A.R.T. la princesa Letizia la cual me ha dado marcadísimas pruebas de una gentil y benévola estimación. He conocido a Mascagni. He cantado y tratado sucesivamente a Toscanini, a Beider, que, es hijo político del gran genio Wagner, al célebre Keller, a Bonei, a Tamagno, a Barrientos, a Tetrazzini, a Giordano, a Puccini, a Zandonai, a Leoncavallo, al inmenso Zaccone, al gran es. cultor Canónica, a Carusso, a Battistini, a Titta Ruffo, a Bistolfi el insigne escultor, a la Duse, y a Saint Saens, cuya ópera Les Barbares, estrené yo en el Liceo de Barcelona. También podría 
citarles como grandes amigos míos a Guido Bacelli, Maragliano, Novaro, Veratti, Durante, celebridades científicas. De Francia recuerdo mucho a Calvé, Delmás, Renaud, Van Dyck y Litivyne. En España nunca olvido al insigne Benliure y al inmenso Sorolla.

Me gusta, me seduce el arte. Tengo en mi casa de Milán una pequeña pinacoteca

- ¿Cuáles son sus actores favoritos?

-En música, Wagner. En literatura, fui, en mi infancia apasionado de Manzoni. Leo a Togazzaro, a Carducci; me encanta la fuerza y la belleza de la obra denunziana.

- ¿Piensa usted retirarse de la escena? renta..

-Cuando llegue a los cincuenta años. Tengo apenas cua-

- ¿Cuál es su obra favorita?

-Mefistófeles...

-Usted hace con mucho cariño el papel de Mefistofeles.

-Es curioso observar la diferencia de creación entre el Mefistófeles de Boito y el diablo de Fausto, de Gunod. El diablo de Mefistófeles es el puro espíritu filosófico del mal. Vea usted como se presenta a Fausto:

- Sono lo spirito che nega

Sempre tutto, lastro é il fior

Il mio ghigno e la mía bega

Turvanolbozio al Creador!

En cambio en Fausto, el diablo es un gentil hombre, un Don Juan, que dice:

-Sono qua ¡Perché tale sorpresa!

La voce tua da mé fu intesa.

El fianco l'aciar ¡La piuma al cappel

La scarsella piuma! $\mathbf{E}$ un rico mantello nel

Un vero, é un bel cavalier!...

-Es usted un demonio magnífiç, señor Nicoletti. . .

-Es favor...

-No, es justicia.

- ¿Qué hombres ilustres conoce Ud.?...

- El recuerdo más dulce y más glorioso de mi vida es el que guardo de Verdi. Era yo muy niño cuando conocí al ilustre autor de Aída... Conozco también a D'Annunzio, a San Benelli, ¿para qué citar nombres?..

- ¿Es usted casado?...

- La donna e movile cual piuma al vento!... 
Soy desconfiado...

- A mí me parece que a medida que es más movile es más encantadora, que quiere usted...

-Puntos de vista, amigo.

Sono una campanilla. El Diablo comenzó a vestirse. Nosotros salimos. Por un instante nos detuvimos a observar los bastidores. Los bastidores son un mundo especial. Cruzaban, cerca de nosotros, los más raros personajes. Una bailarina, vestida de bruja, ensayaba un poco levantando la pierna eburnea, blanca y empolvada. Diablitos pequeños, vestidos de rojo, con caperuzas bicornes hacían piruetas.

En un rincón, un empleado de la empresa pagaba su salario a los demonios importados... de la calle. Hombres rojos, con tridentes enormes contaban monedas de a sol. Pasó muy cerca, dejando un perfume capitoso y peculiar, una dama griega, por los pliegues de cuya túnica una obesidad agresiva surgía amenazadoramente. Un hombre con los lentes encaramados en la nariz monstruosa, indicaba una frase. Conversaban animadamente junto a un árbol de cartón, dos damas griegas, viejas, tuertas y desdentadas. Sobre una banca rústica, la misma banca en que se sienta Pagliaceio a llorar la perfidia de su colombina, un traspunte 1 leno de granos se hurgaba la nariz. Gritaba obscenidades en ităliano; encolerizado, en riña con el maquinista, un joven pibimeraviolínras

Un hércules chilenorgregrordietevyssudoroso, cargaba con un pedazo de muro de papel aventanado y nos atropellaba con el muro frágil. De pronto comenzaron todos a correr fantásticamente. Sonó un nuevo campanillazo y se hizo la luz.

El telón comenzaba a levantarse.

$\mathrm{Y}$ nosotros salimos del infierno...

(De LA PRENSA, 22 de noviembre de 1916)

VI

\section{EL HOMBRE QUE HACE DORMIR}

Conversé de esta manera, en la solemnidad de la tarde, bajo el cielo preñado de ideas, con Onofroff, el hombre de las pupilas de ofidio.

$-i$ No es en este tumultuoso lugar, nido de gentlemans, criadero de bellacos, rendez-vouz de entalladitos, panal de miel de bebedores, especie de academias de parlanchines, que llamamos. Palais Concert; biselado salón que se engala, a veces, con la magnífica y señorial belleza de las gentiles damas limeñas, graciosas, inteligentes, expertas en miradas y en sonrisas cuan- 
do jóvenes, de lindas manos tersas y finos pies breves, ¿dónde podemos conversar señor Onofroff de cosas trascendentales?

Conversaremos y tendré la noble complacencia de oiros y de que me escuchéis. Se está mejor para divagar sobre los nobles temas, en el campo bajo de la bóveda pensativa, ante un paisaje que tenga el don al par sereno e inquieto, de hilar nuestras ideas, de engarzarlas, y de poner sobre la conversación, las dos grandes virtudes que son el alma de la música: la armonía y la melodía. Hablemos de la muerte, del misterio, de la idea pura, del espíritu, de la onda intangible, del silencio del espacio constelado y de este pequeño mundo trascendental, parecido y diverso, complicado y sencillo, de una fuerza vital engendradora de la muerte, de este conjunto de pequeñas verdades, conexas y esquivas, que se llama el organismo humano, de esta intrincada fuerza dual que produce la maravillosa unidad biológica donde es reina y señora la Conciencia. Hablemos senor Onofroff, de la conciencia misma, de la voluntad, de la razón del instinto. Ingresemos, por un instante, lejos de estas calles congestionadas, a ese mundo que marcha, evoluciona, nace, crece, muere, resucita y concluye cada día, a cada instante, a cada segundo...

Y llevé, al hombre largo pálido, elegante, de ojos vidriosos e inquietos, al encantador rincón limeño a cuya espalda se levanta la calaminada estación de Chorrillos, y a cuya derecha, severo y alegre a un tiempa con da serenidad clásica y la clá. sica alegria, se yergue blancoplimpoluto, el Palacio de la Exposición, tras el cual apuntaba el pálido cielo de un crepúsculo palúdico y en cuyas cornizas los gallinazos, "grotesco trasunto de los trágicos cuervos de Edgard" símbolos de la nacionalidad, ponían la mancha de su criolla silueta ófrica, tal como sobre un dulce azucarado de bodas, se peyaran ávidas las moscas, otro símbolo de la nacionalidad... y hablamos de esta manera:

$-i$ Creeis en Dios, señor?

-¿Cuál Dios?...

-El Dios del Catecismo, el Dios de la Historia Sagrada, el Dios de la Escuela, el Dios amado de mi corazón, el Dios de la tímida, de la casta paloma. Y del triángulo equilátero, el único Dios que puede existir, porque es el que me enseñó a conocer mi madre. Yo no quiero que haya otro Dios. ¿Usted cree en ese Dios, en mi Dios?

-Como hay razón y hay sentimientos, hay fuerzas y hay conciencia, para la razón hay el Dios fuerza, para el sentimiento hay el Dios conciencia...

- ¿Pero la causa, el origen, el principio? 
-Células...

- ¿Y las células?

-Principio vital.

$-¿$ Y el Principio vital?

-Atracciones, vibraciones, ondas, calor, movimiento, vida, transformaciones...

El crepúsculo se encendía, se ençendia, se encendía. En el fondo de púrpura, los árboles recortaban sus pequeñas hojas, sus finos tallos y su espeso follaje, caminábamos hacia el fondo, hacia donde el paisaje se torna vulgar y heroico, decorado por el movimiento ameno de un anciano glorioso. Rompí el silencio para apuntar...

- ¿Y la muerte, Onofroff?...

- Hija de la vida, condición de la vida misma. Cada ser organizado, usted, yo, aquel, somos pequeños cementerios ambulantes. Contínuamente muere una parte de nuestro organismo y otra parte renace. Expelemos cadáveres de células. Y usted sabe que en la célula....

-Reside la íntima sustancia vital.

- Cada once años más o menos se renueva completamente nuestro ser y no tenemos en nuestro organismo, nada, nada, nada, de lo que teníamos-once años antes. Muere el hombre, por partes, varias veces. Perrece todo lo tangible, sólo perdura lo íntimo, lo imponderable, la conciencia. Usted conoce una célula, es lo que se podriablilanteardenatisíntesis biológica. En cllas hay cuerpo y alma, confosentrénelinfidaderarmónica que es el hombre. La célula nace, crece, se desarrolla, se nutre, tiene conciencia, vibra, se defiende, se asocia, obedece una ley, controla otras leyes, engendra; se diría que piensa, es, en suma, un pequeño animal...

- ¿Luego cree Usted en el alma?

-Creo..

- ¿Muere el alma?

Sería espantoso.

- ¿Cree usted en el espiritismo?

-No creo.

- ¿ $\mathrm{Ha}$ leído usted "La Muerte" de Maeterlinck?

- Sí, pero no hay conclusiones. El poeta ama la muerte... Sólo se puede ser racionalista, sólo se puede negar la supervivencia del espíritu ante un cadáver; el espectáculo de la muerte es el principio de Filosofía que niega...

- ¿Usted, Conde de Lemos, es espiritualista?

-Onofroff, le confió a usted estas verdades experimentales y definitivas, pero escúcheme con calma y no me interrumpa, ahuyentaría usted mis ideas que son tímidas como palomas. 
Aquí abajo el cielo, las estrellas son como granos que ellas sa. len a buscar. Oídme. He estudiado Histologia. Ninguna ciencia es superior a esta ciencia que las encierra todas; ningún camino es más seguro que este camino del cual parten todos. La razón es cíclope; mira por su ojo único: el microscopio; el pensamiento, la fantasía, lo que nos lleva a lo hipotético, es cíclope también; mira por su ojo único: el telescopio. El espíritu humano, en suma, tiene dos ojos para el análisis de lo trascendental: el microscopio y el telescopio. Hay además, dos grandes mapas, en cuyo contraste reside el Misterio, la Verdad, por revelarse, la Causa Unica; el cerebro celular y el pensamiento estrellado. Entre estos dos polos reside todo. Una neurona es como una estrella cerebral; una estrella es como una neurona del pensamiento... ¿Veis ahora en el cielo cómo parpadea Venus?...

\section{-Y continué:}

-Yo tenía un amigo de cincuenta años que me había visto nacer. Yo lo quería como a un hermano mayor. De pequeño me regalaba confites, me decía: "pericote" y me pellizcaba el carrillo. Un día cayó enfermo. Hace dos años se puso malo. Yo le vi en el lecho. Ardía en una fiebre intensa, cruel y sofocante.

Parecía un pedazo de sol. El médico dijo que se moría y comenzó a 'morirse. Entró en la agonía. Diez minutos antes me hablaba con claridad y precisión, su inteligencia penetraba en mí. Diez minutos más tárdecndeme reconocía, pero su cuerpo animaba aún, vivía, vibrabá.

Se murió, se enfrió. Su rostro tenía un aspecto viscoso y en sus pupilas había un líquido blancusco, a manera de una lágrima muerta. Una lágrima muerta al nacer. Metieron el cadáver en un cajón, en actitud incómoda entre las paredes estrechas. Un mechón de pelo sedoso, le caía, como una ala muerta, sobre la frente amarilla, rutilante y extensa. La frente parecía pensar.

Era un sábado, todo el domingo le velamos, le ví inmóvil, con esa angustiosa inmovilidad de los muertos. Una sonrisa triste se había coagulado en su rostro bondadoso. Pero comenzó a descomponerse. Yo tuve un asco medroso y debo confesarlo, Onofroff, evitaba su presencia.

Taparon el cajón y en el cementerio lo metieron en un nicho oscuro, estrecho, de donde se había sacado otro cadáver. En el piso del vano donde habitó el otro muerto, quedaban las orugas de los insectos que se comieron al emigrado. Cerraron el nicho, eran las seis de la tarde y todos, todos, parientes y amigos, dejamos solo al muerto y nos fuimos. Nadie se quedó. 
No tenía objeto. Yo comprendi que allí había terminado todo, todo, todo...

-No; debió quedar la conciencia.

- Oiga usted, Onofroff, Ramón y Cajal, en el capítulo "Neuronas", dice que la conciencia es la resultante de la química celular. Muertas las células, cada célula tienc una fequeña conciencia, su conciencia. El cómputo de todas estas conciencias infinitesimales es la onciencia, la gran Conciencia. De manera que mientras las células, los pequeños componentes... genio?

- ¿Y cómo nos explicamos la inteligencia, el talento, el

-Por la evolución del cerebro.

-Pero si el cerebro muere.

El genio es el resultado de una evolución, de un perfecionamiento celular. Ocurre con los cerebros lo que con los cañones; el último modelo es superior a los precedentes. La línea de continuidad en la cual se opera la evolución sólo se establece en el génesis, en la generación, en la sucesión de vidas.

Habíamos llegado a la plazuela desde la cual los árboles en doble fila se alargaban hasta el mar.

-Diga usted Onofroff, ¿existęla adivinación?

-Wells, el novelista fantástico más sabio, la acepta en una teoría de lo más ingeniosa más yo no creo en ella. Se puede trasmitir el pensamiento que es lo que yo hago con los hipnotizados, ante el públiçipléponolsę quede adivinar. La profecía, si existe, se ajustará a leyesécquelinonconozco y a métodos que no practico.

- ¿En qué consiste segün usted el hipnotismo?

-Yo más que todo lo atribuyo a un dominio absoluto de la voluntad, al dominio de una voluntad fuerte sobre otra débil, así se explican los fenómenos...

La voluntad, esta fuerza cerebral que todos tenemos, que es un don que recibimos de la naturaleza, se puede desarrollar a deseo; en los abúlicos, la voluntad está atrofiada, la voluntad es como un órgano, una fuerza divina irresistible, la voluntad es omnipotente; no hay hombre de voluntad fuerte que haya fracasado. Cuando el talento está acompañado de la voluntad, el hombre es un triunfador. Un máximo talento y una máxima voluntad nos dan esta ecuación:

Máximo talento $\mathrm{x}$ máxima voluntad $=$ genio.

- ¿Cree usted en el destino? ¿Cree usted que cada hombre debe recorrer un camino trazado de antemano?

-No. Creo que cada hombre es hijo de sus obras. Hay una gran palabra que los hombres no saben explotar y que es el secreto de todo triunfo. Previsión. Sed prevenido. El destino es 
un prejuicio. Los hombres harán de sus vidas lo que quieran. Yo tengo una niña, mi hija, usted sabe que los niños sufren accidentes en los primeros años, golpes, caídas, etc.. yo y mi señora hemos cuidado de tal manera a nuestra hija que jamás se ha golpeado. Si los hombres, después de vivir una vida, volvieran a nacer llenos de experiencia ¿quién fracasaría?...

El destino depende de la voluntad, de la acción... ¿No Io cree usted?

-No, Onofroff. Creo que el hombre, el rey de la creación por autotítulo, es la más frágil y deleznable de las criaturas. Esta maravillosa máquina tan complicada, tan delicada, tan fina, es al mismo tiempo la más susceptible de descomponerse, de interrumpirse, de morir. ¿Dependemos, acaso, Onofroff, de nosotros mismos? ¿Puede el hombre hacer su destino? De mi sé decirle que siento la influencia extraña. ¿Qué puede mi voluntad, qué mi deseo? Un mal encuentro, un tono de luz, un día de Iluvia, un crepúsculo, un recuerdo, una palabra, son suficientes para transformar al rey de la creación, mi tristeza, mi alegría, mi felicidad, mi complacencia, mi desesperanza, mi dolor, dependen, Onofroff, de un color del cielo, de una mayor o menor cantidad de sol, de una frase dulce, de una mirada y a veces - oh dolor- de una buena digestión, de una comida frugal, de un pertume severo, de una banalidad. El hombre depende todo. Nuestros actos son acciones reflejas, los muertos mandan, viven en nosotibos; tenada thacemos por propia orientación. Creemos que hay voluntadlifoloreque hay es el mandato severo del destino, de lo ignorado que actúa en nosotros, de lo invisible, que es el propio tiempo inexorable. No somos libres, Onofroff. Nos creemos libres, fuertes, autónomos, porque nos movemos, evolucionamos y discernimos. Pero no olvide usted a Eca de Queiroz: "La conciencia se puede eliminar con un poco de agua de azahar"; se puede acrecentar la inteligencia con la lágrima negra de una adormidera; se puede alternar la razón con un jugo de una planta; depende la salud del bicho microscópico que anida en un tejido: depende la alegría de la cantidad de jugos glandulares; el corazón, el órgano amoroso de los románticos, es un simple motor; y quien sabe si en el bazo en ese órgano anodino e incalificable, especie de parásito del organismo reside el subtractum.

-Qué bien se expresa usted.

- Ni eso depende de mí. Hay acaso cuitas de mi vida. $\mathrm{Ni}$ de eso puedo envanecerme.

- Hábleme, hablemos, todo esto me interesa...

-Ya cae la noche, amigo mío...

-Quisiera hacer el elogio de la noche, pero esto es para el 
público y el lirismo no es periodístico. Y así volvimos a la ciudad. Yo debía haber preguntado a Onofroff haciendo lujo de una fácil habilidad de quienes se dedican a preguntar necedades a los artistas famosos, de dónde es, cuándo se decidió a trabajar en público, qué le parece Lima, pero a quien como Onofroff, le cabe la suerte, de dominar las voluntades y de dormir a las gentes con una mirada o una palabra, me parcció prudente preguntarle lo ya transcrito. Asi nos despedimos en silencio, mientras la noche caía solemne y compacta, sobre las arboledas del parque solitario. Seguimos hasta el centro y nos despedimos prometiéndonos volver a conversar de tan nobles asuntos, pero dè esas que serán largas conversaciones, no tendrá conocimiento el público, a quien ciertas cosas no le importan nada...

\section{(De LA PRENSA, 26 de setiembre de 1916)}

\section{VII}

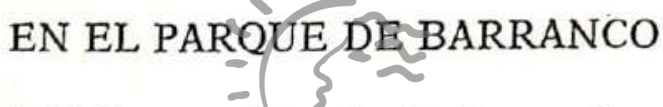

Abraham Valdelomar (Conde de Lemos) está entre nosotros. Ha llegado una de estas tardes de verano, enamorado de la Poesía, de la Belleza bijbet fla paz đea Barranco. Ha venido él mismo lo cuenta- a puirificarli survespíritu, harto de la insultante vulgaridad de la metrópoli, que según dice él graciosamente, es hollín que tizna. Ha cambiado con el mismo gesto de amplia displacencia con que escucha y habla, los "cocktails" y tés aristocráticos del Palacio Concert por los almuerzos en los baños y los modestos aperitales aldeanos. Valdelomar es para Barranco un antiguo conocido. Aquí vivió en épocas pasadas y, como José Juan de Velarde, vuelve después de diez años. El Conde de Lemos ha vivido y vive enamorado de la armónica belleza de este pueblo que se empeña en ser burgués. Si Valdelomar tuviera espíritu mercantil imaginaría fantasiosos y definitivos réclames, que haría publicar en los grandes rotativos capitalinos, pero como es artista, y artista de genio, lo ennoblece con sus alabanzas y le hace el honor de su pluma genial y elegante. Hoy ha dicho a "Balnearios", en frases bellas, su admiración por este balneario sentimental y romántico, y mañana le cantará en versos delicados y sutiles como todos los suyos.

Su morada en este pueblo está en la orilla del mar, que es poética y linda. No pudo escoger nada que estuviera más en armonía con su ecléctico espíritu de artista. Comenzó a reci- 
tarnos unos versos en que canta esa belleza del rincón en que piensa y produce; pero no nos quiso hacer la merced de terminarlos.

Abraham Valdelomar es motejado jOh Gutiérrez QuintaniIla! de ser ensoberbecido, petulante, ridículo poseur y hasta mal literato; ¡blasfemos! aquí en este país de mojigatos y de ventrales, la sinceridad es un crimen, y Valdelomar es sincero, sincero siempre, demasiado sincero quizás. Sus detractores nunca atacan su obra literaria. Los menguados no podrán hacerlo. $Y$ rabiosos de no poder clavar los dientes y destrozar todas las bellezas y genialidades de su producción, se transforman en lobos aulladores de sus acciones, sintiendo, en el fondo, un gran deseo de imitar sus insolentes actitudes y la pulcra elegancia de sus escarpines y de sus blancas camisas de verano. El clasico cintillo negro y blanco que sostiene sus anteojos es la obsesión de todos y, en general, es la figura literaria de su generación que más preocupa al público.

Para "Balnearios" tiene Valdelomar distinta y más valiosa significación. En esta casa se le conoce, se le admira, y se le quiere. $Y$ si no exageramos la alabanza, tampoco nos atrevemos a burlarnos, ni a zaherir a quien como él, es el mejor y más completo escritor de su generación. Su presencia en el pueblo tiene especial importancia, y "Balnearios" no deja de sentir orgullo al presentaruo, publicando una conversación que sostuvo con él una de estas lunadas y sentimentales noches barranquinas, bajo la protección poética y perfumada de Ios jacarandás.

A Valdelomar no le disgustará, seguramente, que lo presentemos tal cual es, finamente humorista, con humorismo que no todos alcanzan, atrevido, y sobre todas las cusas. sincero. En sus palabras encontrarán -quizás- los espíritus timoratos y raídos por la espantosa realidad del fracaso o de la esterilidad, campo propicio para ensayar un destemplado concierto de aullidos; ante sus atrevidos juicios se espantarán los cerebros encasillados que sólo aplauden lo que la crítica aplaudió, sólo admiten las reputaciones que tienen siglos, por más que no entiendan la belleza y arte que originaron y sólo creen en el talento de la gente seria y reposada, que ha copiado esa actitud de la pacífica y concienzuda serenidad del asno.

Nuestra conversación, que tiene los horrores de un reportaje, fue así:

- ¿A qué ha venido Ud. a Barranco?

- A lavar mi espfritu en la diafanidad del cielo y a perfu- 
marlo luego con el perfume de los campos. Oiga Ud., mi esplritu es como una gran ánfora griega que suele enhollinarse con la vulgaridad de las gentes metropolitanas. De esta suerte, la vulgaridad es el hollín del espíritu. Aquí en esta encantadora y paradisíaca villa ennoblecida con los versos de tantos poetas y la música de tantos prosadores, aquí donde resuena siempre, aunque lejana, la lira multicorde de Eguren, yo he sentido rejuvenecer mi alma: he vuelto a ser infantil. La infantilidad es al hombre como la salidad del sol a la naturaleza.

-iAy del cuitado que no vive y ve con el sol antes de que llegue al crepúsculo!

- ¿Le gusta a Ud. sinceramente, Barranco?

-iSinceramente! he aquí una palabra oportuna. Las gentes dudan de mi sinceridad. Porque si yo no fuese sincero, ¿podría ser un artista? Soy sincero y la sinceridad mana de mi corazón sereno y sin esfuerzo, como el agua clara brota de la roca en el barranco, florecido. Llevo mi corazón en las manos, sangrando y tembloroso de emoción por toda la Belleza que Dios ha puesto sobre el mundo; que si lo oculto a veces no es por pueril mediocridad, sino por una piedad ingenua por un azul candor de que me lo-quilen, de que le hagan daño. Cuando llevamos nuestro corazón en las manos las gentes gustan de hacerlo sangrar. Malas $y_{b}$ menguadas son las gentes. Yo no quiero a los que pegan a los.corazonestipo quiero mucho los corazones! Hay cholos que se complacen en dañar corazones. ¿Ud. no conoce mi corazón? No lo ha visto llorar por los males del mundo, por la lamentación de los bandidos, por la muerte del sol, por el alma sin primavera de los estériles y de los malvados? ¿Por qué me pregunta si soy sincero? Yo digo lo que siento, amo lo que es bello y realizo mi arte, lo mismo que canta el jilguero y florece el jacarandá y el sol alumbra. Hay dentro de mí una fuerza sobrenatural que me dice: crea, piensa y canta!

Pero, ¿le gusta Barranco?

-Me gusta. Aqui pasé los días tristes de mi primera juventud, oscura y pobre, pero el alma del pueblo recién llega a mí. Me gusta tanto Barranco que su nombre me disgusta. Este gentil recodo de la naturaleza, debiera llamarse Jericó por sus flores, Samos por su belleza serena, honda y jovial, Sorrento por sus tapialerías donde las vides trepan...

- ¿Qué le gusta más de Barranco?

-El rincón azul de los jacarandás, las avenidas sobre el mar, las noches de luna sin profanación del voltio y del amperio, sus calles arboladas sin la insultante velocidad del caballo 
de fuerza, la gruta cándida de la virgen, la palmera que se abanica en el parque; la conversación de todos ustedes.

- ¿Le gusta a Ud. lo que hablamos?

- Sí, pero más aun cuando me escuchan... Me gusta el almuerzo en los Baños, mı casa sobre el mar, las azules campánulas que tejen su espesa malla en los barrancos, los encañados que medran entre las abras, la inefable canción del mar, la gracia original del Sr. Colich, el cielo, el mar, los árboles.

- ¿Qué hace Ud. en Barranco?

- Lo que en todas partes. Soy un esclavo del Destino. Cumplo con un mandato inexorable: hago arte.

- ¿Escribe Ud. algo?

- Versos, versos, versos. Lindos versos. Leyó Ud. mi Epístola lirica?

$¿$ Recuerda aquel verso?

Alma lírica hermana á través del camino, bajo la noche azul, serenay constelada, cuando los dos hayamos derrotado al Destino...

Bello ¿verdad? En aquellos versos hablaba de Baranco:

\section{Bíblioteca de Letras}

Mi casa, sola praya, paces comor una atalaya

ante ella marina ola enérgica estalla,

$\mathrm{Y}$ luego en un encaje de espuma se desmaya...

Pero la mejor pintura de mi linda casita es la que hago en un soneto. Escuche:

Trepadora campánula, pródiga en flores lilas,

- verde festón- de la terraza pende;

la brisa persistente sus nobles alas tiende:

en el cielo, las nubes se dispersan tranquilas.

El crepúsculo lleva sangre de sus pupilas

y mi alma que su casto y hondo dolor comprende

a la muerte del sol, lírico cirio enciende,

y en las torres lejanas se quejan las esquilas...

-Qué lindo, continúe...

-No. No quiero hablar. Hoy estoy inteligente: hoy quiero escribir. Qué cosas tan nobles podrían escribirse bajo la paz li- 
la de estos jacarandás de Barranco. Qué dulce y honda emoción tendría ese artículo. ¿Habrá quien no quiera sus artículos? Yo quiero mucho lo que escribo, cuando tenga hijos yo los querré tanto como a mis artículos...

\section{- ¿Cuál es su autor favorito?}

-Depende de las estaciones. En invierno me gustan las misteriosas tragedias de Maeterlinck. En otoño leo a Kempis, porque Kempis es otoñal. En primavera, en los días luminosos que aun no tienen el calor procaz del estío, me gusta Pitágoras. Pitágoras es abstracto y diáfano como un cielo de primavera cuyas nubes estuvieran preñadas de ideas. Pitágoras me hace el efecto de Colón, perdiéndose en los bosques de su tierra descubierta. Porque Pitágoras descubrió el número, el ritmo y la cadencia pero se perdió en divagaciones geniales: no llegó a precisar leyes. Y sólo la ley es verdad. En verano, leo a Rudyard Kipling. Kipling! A su lado fracasa Anatole France y resulta soso Voltaire. Pero ahora me entretengo con los versos de Robert Browning. ¿Conoce a Browning? ¿Se acuerda de aquel verso de la pluma de águila?

$-¿$ Qué clase de escritores prefiere Ud.?

Bibligteca de Letras

- Los de un profundo lirismersbiril, el gran poema a lo Whitman, a lo Chocano, la fantasía a base de una profunda ciencia como Wells, pero, sobre todo, la verdad de la vida diafanizada por un alto y dulce humorismo. Porque la vida es una gran tragedia que a veces da risa o es vulgar como una ridícula zarzuela llena de sangre. Por lo demás yo tengo una estética mia, propia, experimental. El valor estético más poderoso para mi, es objetivamente el que tiene más dosis de sugerncia y subjetivamente el que penetra más en el misterio. De allí mi admiración por Maeterlinck. Maeterlinck morirá loco. Es el genio que más ha penetrado en la sombra en pos de la Verdad Esencial. Me place Virgilio (oh Manus inerte tenebras), Horacio, Platón, Pitágoras y Esquilo... Oiga Ud., yo no quiero del todo al Dante. Hay párrafos del Dante que son una especie de tunda escrita en versos divinos. Admiro al Dante de la Vita Nuova, al Dante que no insulta, al Dante que no tiene la petulancia de tomar por cicerone a Virgilio. Porque Virgilio en la Divina Comedia es el cicerone de Dante. Y Ud. sabe lo que son los cicerones italianos. Yo los conozco... .

- ¿Ama Ud. la vida? 
- Sí, la amo, pero no estoy enamorado de ella, porque la amo con una gran inquietud. Yo soy un torturado.

- ¿Por qué?

- Porque hace dos años tengo delante de mí dos caminos. Ramón y Cajal y los positivistas me convencieron de que todo concluye con la célula, pero un día vi el cielo con el Telescopio y pensé en Dios. Yo no creo en un Dios con triangulito y con paloma en la cabeza. Soy cristiano sincero, creo en Dios, fuerza inefable, incorpórea, perfecta y justa. Cuando yo resuelva el problema de la supervivencia del espíritu me suicidaré...

- ¿Por qué?

- Por curiosidad. La vida es simple lugar de tránsito. En la vida somos pasajeros de un hotel más o menos confortable. No deben interesarnos las veinticuatro horas que vamos a pasar en el hotel sino el largo tiempo que vamos a estar fuera de él. Oh qué nos importa la vida? Son cincuenta, sesenta años. Debe importarnos el más allá: millones y millones de siglos, lo definitivo, lo inevitable, lo que ha de venir. Acuérdese Ud. de mis versos:

Vendrá la muerte un día con su hoz enarcada, nos tenderá los brazos al fin de la jornada.

\section{Biblioteca de Letras}

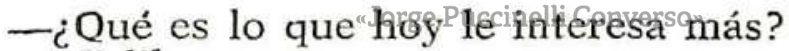

Mi libro.

- ¿Qué libro?

-Estoy escribiendo un libro sobre la estética del toreo, sobre el genio fantástico de Gaona. Voy a revelarle a la estética un arte nuevo. Gaona es el substractum de la Estética contemporánea. El arte universal se reune en él...

- ¿De qué hablara su libro?

-Del arte del toreo, del arte que los escritores no han visto aun o por lo menos no han manifestado todavía. Estudio la línea, el color, la actitud, los planoș. El toreo es estatuario, pletórico y musical, porque la música es ritmo. El toreo es además la vida entera: comedia, drama, tragedia. El toreo es la Danza. ¡Y Ud. sabe lo que es la Danza! Es la danza íntegra realizada delante de la Muerte. Es un símbolo sublime del arte, ante la muerte. Cuando yo he visto a Gaona, he salido deprimido por la enorme emoción, por la tensión nerviosa que sufro. Vivo una vida en los toros. Ningún artista me ha hecho sentir más 
arte que Gaona. El toreo es un arte integral, viril, emocional, sensual, quizás humano y estimulante.

\section{$-¿$ Conoce Ud. a Gaona?}

-Es muy amigo mín. Mi libro ha de gustarle. Ya hemøs conversado mucho sobre ello.

El Conde de Lemos se queda silencioso. Apoya la cabeza en la diestra donde brilla una piedra oval y verde en el índice.

-¿Qué piedra es?

-Esa piedra es un poema de amor, el más intenso de mi vida, lo llevo en el índice porque el indice es el dedo más noble Es el dedo de la voluntad, el que indica, el que ordena, el que señala, Cristo hacía uso de él en las parábolas. Esta piedra verde esperanza es el oriflama de mi Destino, el símbolo de mi vida; quiero así significar que sobre mi voluntad fuerte y firme llevo el color natural de una esperanza de piedra... más?

-De nuestros escritôres naciònales ¿a quién admira Ud.

-A González Prađali@ohablemgs de literatura. Me carga el tema. Si, verdadJor Koumelladmiro. . O Oiga Ud. yo he conocido a un hombre extraordinario, a un gran profesor de energía, a un talento extraordinario, a un conversador lleno de una ironía a lo Piérola; yo quisiera ser su secretario. Ser secretario de un hombre de gran talento.

\section{—¿Quién es?}

-Don Horacio Ferreccio. Imagínese Ud. a un hombre millonario que declara que el dinero no tiene importancia; que sólo tienen importancia los ideales. Un millonario que tiene ideales, un millonario que sabe pensar como un artista, que es espiritual, que es gentleman. Yo estoy sorprendido y he pensado largas horas en lo que podría ser ese hombre si hubiera nacido en Francia.

$-¿$ Conoce Ud. mucha gente en Barranco?

- Sí, a mucha, pero trato a muy poca. Conozco a los Lavalle. Los Lavalle tienen un gran talento, sin vuelta de hoja. José Antonio es un romántico de las plantas. Si escuchara Udd. 
lo que dice sobre la vida de los árboles. Sobre la sicología de los metales que se aman, los que se odian, los que no tienen voluntad y los que triunfan. Es poemático... a Juan Bautista todos lo conocemos y a Hernando lo conoceremos pronto... Conozco a Beingolea - iYo quisiera tener el gran talento de Beingolea!, conozco a Eguren, al genial Eguren, al delicioso Gar San Gú. Cuando yo me iniciaba hice esta frase rotunda: "Creo en la divina insolencia de Gar San Gú". Conozco a Colich. Colich me entretiene, me emociona, se complace escuchando mis frases sonoras, cortadas, hechas de puntos seguidos. Colich parece una ele trazada por un octogenario delante de un toro de Asín: una ele que temblara. Colich tiene un defecto. Dicen que tiene mucho dinero. ¿Es cierto eso?... Conozco también a nuestra primera autoridad. Yo quisiera darle la lata a nuestra primera autoridad, porque eso es muy humano, pero si digo a él las cosas gratas que merece, van a creer que lo adulo. Conozco a Alfredo Muñoz. Yo le he dedicado un artículo muy lindo, un cuento, a Alfredo Muñoz... ¡Ah! también lo conozco a Ud. Ud. es inteligente.... ¿Por qué es Ud. tan preguntador?... Son las 6. Xámonos de aquí. Yo no quiero estar aquí. Esto me abunre. Ya comienzan a llegar hombres gordos. Me manchan el paisaje. マáyase Ud. un rato. Déjeme. sólo. Al crepúsculo prefiero estar solo. Pero no se moleste. Yo soy más amigo del crepúsculo que de Ud. Véalo qué lindo: sangre, sangre, sangre, nubbes,oídease tristeza, muerte.

"Jorge Puccinelli Converso"

(De BALNEARIOS, Barranco, 14 de

enero de 1917, año VII, № 293)

\section{VIII}

\section{BREVES INSTANTES CON SANTOS DUMONT}

En el palacio de la Legación del Brasil — Santos Dumont: un metro treinta; calvicie prematura; nariz fina y anhelante; bigote americano, diminuto y negro; labio inferior brasilero; boca "smisurata"; sonrisa perenne; ojos expresivos y gordos. Magro, ágil, gentil. insinuante, de discreta elegancia. Parece no darse cuenta de su gloria. Está rodeado de diplomáticos, escritores, políticos. Presentación, apretones de manos, frases de homenaje. Se siente atmósfra de gloria. Dumont sonríe, modesto.

Valdelomar:

-Vibro de entusiasmo ante vuestra gloria, Señor... 
Dumont:

-Estoy muy agradecido. Son muy gentiles los peruanos.

Valdelomar:

- COLONIDA, mi revista que usted ya conoce, le pide un autógrafo.

Dumont:

-Enchantée, monsieur!

(Un mayordomo en frac azul de prusia y clorada botonadura, ofrece una pluma a Dumont que escribe):

Un saludo para los lectores de "Colónida".

A. Santos Dumont

Valdelomar:

- Gracias en nombre de esas ilustres gentes. Diga usted, señor, ¿ha escrito usted versos alguna vez?...

Dumont:

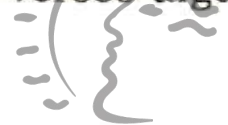

-Nunca. Pero seducenecHeescrito un libro sobre aviación que se editó hace nuevegaños en París.

Valdelomar:

—¿Cuál es su poeta favorito?.. .

Dumont:

-Camoens, Alencar... Ils sont si marveilleux.

Valdelomar:

- ¿Y de los poetas franceses?

Dumont:

-Víctor Hugo... C'est le plus grand.

Valdelomar:

-Et Verlaine... vous plait-il? 


\section{Dumont:}

-Verlaine, c'est la grace musicale, la supréme harmonie. Mais Hugo c'est la force, la grande force epique...

Valdelomar:

- ¿Conoce usted a Anatole France?...

Dumont:

-Es gran amigo mío. Así también Henry Rochefort, el director de "L'Intransigeant". Hemos comido una noche juntos. poco antes de salir de París, con el presidente de la república...

Excmo. Señor Alencar:

-Un cigarro, Dumont. Valdelomar ¿un kummell?

Valdelomar:

-Gracias, Excelencia.

Dumont:

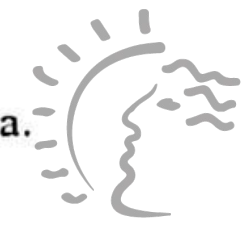

(Acaricia la rubia cabellera de tuna linda flor peruana, una encantadora criatura, hija de un alto empleado de Relaciones y de una gentil dama brasilera a la cual vuelve a ver Dumont después de veinte años. Se han conocido en París. Evocan días pasados en la Ciudad Luz. El señor D'Alencar obsequia flores a la dama y a la "charmante fille").

El señor Alencar:

-Café noir, Dumont?

(El fotógrafo ruega a los ctrcunstantes una pose, e imprime varias placas).

Valdelomar:

-Volverá usted al Perú. Señor?

\section{Dumont:}

—Lo deseo vivamente; quizá... ¿No van los delegados peruanos al Chilí? 


\section{Valdelomar:}

- Llegarian tarde.

\section{Dumont:}

- Conviene alentar la aviación que para ustedes tiene ya páginas de gloria inmortales.

Valdelomar:

- Y trágicas.

Dumont:

(Musita con religioso respeto, como recordando un sueño): naud!

—Chávez... los Alpes... La gloria... Bielovucic... Te-

El Excmo. Sr. Des Portes de la Fosse:

-Vous avez connu Whrigt?

Dumont:

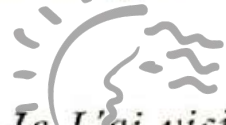

Je le connais bien. Je L'ai visité chez lui au Etates Unis. Il souffre de paralisie. C'est terrible!... C'est affreux... Oh!... $\mathrm{Oh} !$. .

\section{Biblioteca de Letras}

(El Excmo. SeñorgAlenoarcsaconel remontoir. Es la hora. Hay que partir. La concurrencia se despide del gran hombre que ha dejado una impresión imponderable en el alma de los admiradores de su genio).

Valdelomar:

-Permitidme que os felicite, Señor, por vuestras hermosas declaraciones en favor de Paz y por vuestra aversión a las fiestas de toros publicadas en los diarios...

Dumont:

-Oh! Gentil, gentil...

El auto desde la puerta:

—Rumb... Rumb... Rumb!... Sisssss...

(Publicado en COLONIDA, Lima, No 3, 1916, p. 3-5, Año I, Tomo I.) 